\title{
O Epodo X de Horácio e a recusa do gênero épico
}

\author{
Alexandre Pinheiro Hasegawa
}

\section{Horatil Epodon Liber X}

Mala soluta navis exit alite

ferens olentem Meuium; ut horridis utrumque verberes latus,

Auster, memento fluctibus;

niger rudentis Eurus inuerso mari

5

fractosque remos differat, insurgat Aquilo, quantus altis montibus

frangit trementis ilices,

nec sidus atra nocte amicum appareat, qua tristis Orion cadit,

quietiore nec feratur aequore

quam Graia victorum manus,

cum Pallas usto vertit iram ab llio

in impiam Aiacis ratem.

$O$ quantus instat nauitis sudor tuis tibique pallor luteus

et illa non uirilis heiulatio, 
HASEGAWA, Alexandre P. O Epodo X de Horácio e a recusa do gênero épico.

preces et auersum ad lovem,

lonius udo cum remugiens sinus

Noto carinam ruperit.

Opima quodsi praeda curuo litore

porrecta mergos iuverit,

libidinosus immolabitur caper

et agna Tempestatibus.

\section{Epodo X de HorÁcIo}

Solta, sob mau augúrio, parte a nau, levando o fedorento Mévio;

para açoitar, ó Austro, um e outro lado, lembra-te das terríveis ondas;

que espalhe o negro Euro, c'o revolto

5

mar, cordas e remos quebrados;

que se insurja o Aquilão, qual n'alto monte

ao quebrar a tremente árvore;

nem surja um astro amigo n'atra noite,

onde se põe o triste Órion;

que, por um mar mais calmo, não se leve

que a nau grega dos vencedores,

quando Palas, de ílio em chama, irou-se

contra o ímpio barco de Ájax.

Ó quão grande suor sobre os teus nautas;

sobre ti, a palidez lívida,

e [depois] a lamúria não viril,

e súplicas ao avesso Jove, 
quando romper a quilha o golfo iônio, mugindo pelo Noto úmido.

Se a boa presa, estendida sobre o curvo

litoral, satisfizer as aves, imolar-se-ão para as Tempestades

uma cordeira e um bode lascivo.

\section{COMENTÁRIO:}

\section{Do metro:}

Embora não possamos caracterizar o iambo apenas pelo metro, já que Catulo, por exemplo, compôs poemas iâmbicos (1) em hendecassílabo falécio, muitos utilizaram-se freqüentemente do pé iambo (uma sílaba breve seguida de uma longa) para compor as suas invectivas e imprecações, como Horácio, no Epodo 10, que analisaremos aqui brevemente. Os dois primeiros versos - ou o primeiro dístico (a estrofe iâmbica) - desse poema são paradigmáticos, pois o próprio gramático Diomedes (2), ao caracterizar o iambo, material e metricamente, escolhe-os como exemplo:

lambus est carmen maledicum plerumque trimetro versu et epodo sequente compositum ut

Mala soluta navis exit alite ferens olentem Maeuium.

Appelatum est autem para \to $\backslash$ iambilzein, quod est maledicere. Cuius carminis praecipue scriptores apud Graecos Archilocus et Hipponax, apud Romanos Lucilius et Catullus et Horatius et Bibaculus.

["lambo é o poema maledicente, na maioria das vezes composto de um verso trímetro e de epodo, como

'Solta, parte a nau, sob mau augúrio

levando Mévio fétido' (Horácio, Epodo X, 1-2) 
HASEGAWA, Alexandre P. O Epodo X de Horácio e a recusa do gênero épico.

É assim chamado por causa de iambízein, isto é maldizer. Desse tipo de poema são precipuamente autores entre os gregos Arquíloco e Hipônax; entre os romanos, Lucílio, Catulo, Horácio e (Fúrio) Bibáculo." (3)]

Este poema, portanto, como diz Diomedes, é inteiramente iâmbico quanto ao metro, pois todos os versos ímpares são senários - mencionados como trímetros pelo gramático -, enquanto os pares são quaternários iâmbicos - citados como epodos por Diomedes e mais conhecidos como dímetros. Aqui, portanto, Horatium proprio rabies armavit iambo.

Os pés iâmbicos, porém, podem ser substituídos, como comenta Villeneuve (4): "No senário, o tríbaco pode substituir o iambo, sobretudo, no segundo pé; o espondeu encontra-se freqüentemente nos pés ímpares (5); o dáctilo aparece nos pés 1 e 3, e o anapesto, nos pés 1 e 5 (6). No quaternário, o espondeu é muito freqüente no terceiro pé (7), freqüente no primeiro, onde se encontra também, por exceção, o dáctilo. $\bigcirc$ tríbaco encontra-se uma vez no segundo pé."

Para aproximarmos, ainda que palidamente, do verso latino, optamos na nossa tradução pelo decassílabo heróico, para o senário, e pelo octossílabo sem a acentuação na quarta sílaba, para o quaternário. Traduzimos o dímetro por um octossílabo sem acento na quarta para se assemelhar ao verso latino, que não tem cesura. Para o trímetro, porém, optamos pelo decassílabo heróico, que, além da décima sílaba forte, tem a sexta, para se aproximar do trímetro, que, normalmente, tem a cesura no terceiro meio pé, chamada pentemímera, dividindo assim o verso em duas partes ou dois hemistíquios, como o decassílabo heróico.

A escolha do decassílabo tem ainda outra razão para nós. $\mathrm{Na}$ literatura portuguesa, o decassílabo tornou-se o metro do gênero épico, já que Camões, ao escrever Os Lusíadas, utilizou-o para compor todos os seus versos. Como o Epodo $X$ dialoga com a épica e utiliza um metro, o hexâmetro dactílico, também consagrado a este gênero, acreditamos que a utilização do decassílabo 
heróico na tradução produza efeito semelhante ao remeter à poesia épica.

\section{Da matéria:}

A invectiva é clara desde o início e o objeto dela também: Mévio, ou melhor, 'o fedorento Mévio'. Porém, apenas pelos versos de Horácio, não sabemos por que tal pessoa é atacada nem quem é ela. Esse mesmo nome, contudo, aparece nos versos de Virgílio (Buc., III, 90-91), quando o pastor Menalcas, ao trocar injúrias em versos amebeus com Dametas, diz em um de seus dísticos:

Qui Bauium non odit, amet tua carmina, Maeui, atque idem iungat uolpis et mulgeat hircos.

["Quem não odeia a Bávio, ame teus poemas, ó Mévio, 90 e o mesmo junja raposas e ordenhe bodes."]

Colocados simplesmente lado a lado os versos de Horácio e Virgílio, não podemos concluir que o Mévio das Bucólicas seja o mesmo do Epodo, e que, portanto, a invectiva horaciana é contra um mau poeta. Mas, seguindo os comentários de Filárgiro e de Sérvio (principalmente desse último) sobre esse trecho virgiliano e analisando mais detalhadamente os versos epódicos, acreditamos que seja o mesmo Mévio, ou melhor, o que esse nome representa: o poetastro, um péssimo poeta.

Diz Sérvio a respeito dos versos de Virgílio (Comm. in Verg. Buc. III, 90): "90. QVI BAVIVM NON ODIT pro poena ei contingat, ut diligat Maeuium peiorem poetam: nam et Bauius pessimi fuerunt poetae, inimici tam Horatio quam Vergilio: unde Horatius mala soluta nauis exit a lite ferens olentem Maeium." ["90. QUEM NÃO ODEIA A BÁVIO suceda-lhe como castigo que ame a Mévio, um poeta pior, pois Mévio e Bávio foram péssimos poetas, inimigos tanto de Horácio quanto de Vergílio. Donde Horácio (disse): 'Solta, sob mau augúrio, parte a nau,/ levando o fedorento Mévio'."] $\bigcirc$ gramático, portanto, como anunciamos, usa os versos de Virgílio para explicar os de Horácio, identificando o Mévio de um com o do outro. 
HASEGAWA, Alexandre P. O Epodo X de Horácio e a recusa do gênero épico.

Já Filárgiro (Expl. in Verg. Buc. III, 90), curiosamente, ao comentar esse mesmo trecho das Bucólicas, diz não ter encontrado nada a respeito de Mévio, a não ser que ele foi um poeta depreciador de Virgílio: "90. QVI VAVIVM NON ODIT idest Vauius et Maevis poetae, qui Virgilio obtrectauerunt. Duos sui temporis poetas, quorum carmina ob humilitatem abiecta sunt. Vult ergo notare, qui sunt inimici Virgilii, quasi dixisset: Qui Vauium pessimum poetam (amat), et Maevium peiorem amet, ut duplum habeat malum. (...) De Maevio vero nihil repperi." ["90. QUEM NÃO ODEIA A VÁVIO, isto é Vávio e Mévio foram poetas, que depreciaram Virgílio. Os dois poetas são de seu tempo, cujos poemas foram desprezados por causa da sua pobreza. Quer, portanto, denegrir - os que são inimigos de Virgílio -, como se dissesse: 'Quem ama o péssimo poeta Vávio, ame também um pior, Mévio', para que tenha o mal em dobro. (...) De Mévio, porém, nada encontrei."]

Mévio, desta forma, parece representar o poetastro, o Quérilo (8) romano. Entendemos, porém, que não se trata simplesmente de uma briga pessoal de Virgílio e Horácio contra Mévio e Bávio; não temos como provar isso nem acreditamos que tal fato esclareça a leitura dos poemas. Mévio - assim como Bávio - representa a má poesia, que é criticada tanto no Epodo $X$ de Horácio quanto na Écloga III de Virgílio. Examinemos com mais detalhe esse último para que possamos, assim como o gramático Sérvio, entender melhor os versos de Horácio.

Nas Bucólicas, Bávio e Mévio são contrapostos a Polião, figura do bom poeta, elogiado tanto por Dametas quanto por Menalcas, antes de esse criticar os poetastros (Ecl. III, vv. 84-89):

Dametas

Pollio amat nostram, quamuis est rustica, Musam:

Pierides, vitulam lectori pascite vestro. 85

Menalcas

Pollio et ipse facit noua carmina: pascite taurum, iam cornu petat et pedibus qui spargat harenam. 
Dametas

Qui te, Pollio, amat, veniat quo te quoque gaudet;

Mella fluant illi, ferat et rubus asper amomum.

[“Dametas

Polião ama a nossa Musa, embora seja rústica:

Piérides, apascentai uma novilha para o vosso

leitor.

Menalcas

Também o próprio Polião faz poemas novos: apascentai um touro

que já ataque com o chifre e espalhe areia com os pés.

Dametas

Quem te ama, ó Polião, venha para onde se alegra que também tu tenhas vindo; para ele, escorra o mel, e a áspera sarça produza amomo."]

Este é o único momento, entre a troca de injúrias, que Menalcas e Dametas estão de acordo. Os dois elogiam Pólio como um bom poeta, em contraposição a Bávio e Mévio, que são criticados na seqüência (vv. 90-91). Porém, o vitupério e o encômio, como já dissemos e voltamos a insistir, não são aos personagens históricos, ou melhor, ainda que também sejam a essas determinadas pessoas, o poeta usa desses nomes para falar da poesia.

Antes de voltarmos à análise do Epodo $X$, precisamos examinar a que gênero pertencem esses poetas, pois essa informação esclarecerá qual o tipo de poesia vituperada pelos versos horacianos. A resposta para este questionamento está nos próprios versos de Vergílio, com o apoio dos comentários de Filárgiro e de Sérvio e da Ode II, 1, de Horácio. 
HASEGAWA, Alexandre P. O Epodo X de Horácio e a recusa do gênero épico.

Filárgiro, ao comentar o verso 88 da Écloga III, diz assim (Expl. in Verg. Buc. III, 88): "QVI TE POLLIO AMAT idest Asinius Pollio uir tragoedographus est." ["QUEM TE AMA, Ó POLIÃO, isto é, Asínio Polião é o tragediógrafo."]

O outro gramático, ao comentar o verso 84, diz o mesmo acerca de Polião e acrescenta, como apoio, a Ode II, 1 de Horácio (Comm. in Verg. Buc. III, 84): "POLLIO AMAT NOSTRAM QVAMVIS SIT R. M. blanditur iam Pollioni patrono, quem et tragoediarum et historiarum scriptorem Horatius fuisse testatur: nam in secundo carminum dicit de historiis $\langle 1,6\rangle$ periculosae plenum opus aleae tractas et incedis per ignes suppositos cineri doloso, item paulo post $<9>$ paulum severae musa tragoediae desit theatris. Quem carmen suum, licet rusticum, tamen amare confirmat." ["POLIÃO AMA A NOSSA (MUSA), EMBORA SEJA (RÚSTICA). Lisonjeia agora ao patrono Polião, que Horácio atesta ter sido historiador e tragediógrafo, pois no segundo (livro) de Odes diz a respeito das histórias $\langle 1,6\rangle$ 'praticas um gênero cheio de perigos e caminhas pelo fogo sobposto à cinza ardilosa', novamente (Horácio), pouco depois $<9>$ 'A Musa da severa tragédia renuncia um pouco aos teatros'. (Dametas), entretanto, afirma (que Polião) ama o seu poema, embora seja rústico."]

Podemos afirmar, por essas citações, que Polião representa o gênero elevado, pois foi historiador e tragediógrafo, como testemunham Horácio e os gramáticos citados logo acima. Além disso, a concessiva - quamuis est rustica (v. 84) - leva-nos a concluir que Polião, embora pratique o gênero sublime, ama também o humilde, como, por exemplo, o bucólico. Nesse trecho da Écloga III (vv. 84-89), portanto, há um diálogo entre os dois gêneros, o épico e o bucólico.

Porém, em seguida (vv. 90-91), ao criticar Bávio e Mévio, temos a confinidade entre a poesia a bucólica (Écloga III) e a iâmbica (Epodo X): nos versos de Vergílio, há a troca de injúrias entre dois pastores e a crítica a Bávio e Mévio; nos de Horácio, a invectiva contra Mévio. Ou seja: os dois poetas vituperam, mas 
esse é grosseiro e explícito (Mala soluta navis exit alite,/ ferens olentem Maevium), enquanto aquele é mais elegante e implícito (Qui Bauium non odit, amet tua carmina, Maevi,/ atque idem iungat volpis et mulgeat hircos.), com o uso do adynaton, para dizer quão absurdo é não odiar tais poetas e seus versos de má qualidade.

Até aqui, então, vimos que Vergílio, na Écloga III, elogia a poesia elevada de boa qualidade, figurada por Polião, e critica a má poesia, figurada por Bávio e Mévio. Não conseguimos, portanto, identificar a que gênero pertencem os poetastros. Porém, se os versos de Vergílio calam a respeito disso, os de Horácio declaram. Dessa forma, assim como usamos os versos das Bucólicas para esclarecer os do Epodo, façamos o caminho inverso na busca de identificar a que gênero pertencem Bávio e Mévio.

Percebemos, pela leitura do Epodo $X$, que a invectiva não é somente contra a poesia de má qualidade, genericamente, mas também é contra a poesia épica de má qualidade, pois deseja para Mévio a mesma sorte de Ájax (vv. 11-14), personagem épico, que blasfemou contra Palas, e, por isso, morreu (Hom., Od., IV):

"Ajax de Oileu da Parca foi preado (9)

Primeiro às pedras o lançou de Giras

Favorável (10) Netuno, onde escapara

Mau grado a Palas, se ímpio não bramasse

Que era salvo apesar dos deuses;

Eis, da blasfêmia azedo, o rei dos mares 390

Pega do seu tridente e fere a penha

Aos pés de Ajax, que se abismou no fundo

Com porção do rochedo. (...)" (1 1)

Mévio, poeta épico, sugerido pela comparação com Ajax e pelo fato de fazer uma navegação, também deve morrer, pois toma matéria acima de suas forças (Hor., A. P., vv. 38-40: Sumite 
HASEGAWA, Alexandre P. O Epodo X de Horácio e a recusa do gênero épico.

materiam vestris, qui scribitis, aequam/ uiribus et versate diu quid ferre recusent,/ quid valeant umeri (12).) Esta é a impiedade de Mévio contra Palas, a deusa da sabedoria: lançar-se ousadamente ao mar da poesia épica. Mévio mostra-se inepto como poeta, assim com Ajax é um personagem inepto ao desafiar os deuses.

Além da alusão à Odisséia, Mévio caracteriza-se como épico, quando se diz que ele possui marinheiros [v. 15: ... nauitis ... tuis ("os teus nautas")]. Assim como os "amores" de um poeta são os seus versos elegíacos, assim os "nautas" de um poeta são os seus versos épicos. Porém, a esse poeta falta a virilidade característica deste gênero [v. 17: et illa non virilis heiulatio ("e aquela lamúria não viril")]. Ou seja: a viagem marítima de Mévio mostrase fadada ao fracasso.

Temos, portanto, no Epodo $X$, não só uma crítica à má poesia mas também uma recusa ao gênero épico, pois Horácio mais uma vez mostra o perigo da viagem marítima. Esta imagem aparece com muita freqüência nos versos horacianos e em outros poetas: a associação da saída para o mar com a épica. Horácio, como se sabe, em diversos lugares, recusa-se a navegar, ou seja, a fazer a poesia épica, pois Febo, deus dos versos, assim o proibiu

(Ode IV, 15, vv. 1-4):

Phoebus volentem proelia me loqui

Victas et urbes increpuit lyra,

Ne parua Tyrrhenum per aequor

Vela darem.

Querendo eu cantar os combates e as cidades conquistadas, censurou-me

Febo com sua lira que não lançasse meu pequeno barco no mar Tirreno. 
O "pequeno barco" figura aqui a poesia lírica, que pertence ao gênero baixo ou pequeno. $\bigcirc$ "eu" lírico contrapõe a sua parva embarcação à grandeza do mar Tirreno, identificado com o "cantar os combates e cidades conquistadas", matéria própria da épi$\mathrm{ca}$, gênero grandiloqüente, elevado ou sublime. Horácio, portanto, recusa esse gênero, pois os seus ombros não se mostram adequados para carregá-lo.

Lemos também a famosa Ode I, 14 como recusa épica, embora seja consagrada já a interpretação alegórica de Quintiliano (VIII, 6, 44), que lê a nau como figura do Estado. Mais uma vez Horácio, ou melhor, o "eu" lírico manda que a nau não se lance ao mar:

O navis, referent in mare te noui

Fluctus. O quid agis? Fortiter occupa

Portum. Nonne uides ut

Nudum remigio latus,

Et malus celeri saucius Africo

Antemnaeque gemant ac sine funibus

Vix durare carinae

Possint imperiosius

Aequor? (...)

Ao mar te retornam, ó nau, novas ondas!

Que fazes? Ocupa com força o teu porto.

Acaso não vês como nus os teus flancos

de remos estão? Por acaso não vês

O mastro ferido do Áfrico atroz

e as vergas gemendo e as quilhas sem cordas,

apenas capazes de um mar mais feroz? (13) 
HASEGAWA, Alexandre P. O Epodo X de Horácio e a recusa do gênero épico.

Além desses dois exemplos, entre inúmeros outros, podemos citar ainda, como uma clara recusa à épica, a Ode l, 6:

Scriberis Vario fortis et hostium

victor, Maeonii carminis alite, quam rem cumque ferox nauibus aut equis miles te duce gesserit.

Nos, Agripa, neque haec dicere, nec gravem

Pelidae stomachum cedere nescii, Nec cursus duplicis per mare Vlixei, Nec saeuam Pelopis domum

Conamur, tenues grandia, dum pudor Imbellisque lyrae Musa potens vetat Laudes egregii Caesaris et tuas Culpa deterere ingeni.

Quis Martem tunica tectum adamantina Digne scripserit aut pulvere Troico Nigrum Merionem aut ope Palladis Tydiden superis parem?(...)

Forte e vencedor dos inimigos, serás descrito por Vário, sob os auspícios do canto meônio, por qualquer ação que, sob teu comando, o soldado feroz tiver praticado no navio ou a cavalo. Nós, Agripa, não tentamos nem dizer essas coisas, nem a grave cólera do filho de Peleu, incapaz de ceder, nem as viagens 
por mar do dúbio Ulisses, nem a cruel casa de Pélope, pequenos (não tentamos) coisas grandes, enquanto $o$ pudor e a Musa que tem poder sobre a lira imbele proíbem diminuir os louvores do egrégio César e os teus, por falta de engenho. Quem descreverá dignamente Marte coberto com túnica adamantina ou Meríno negro com o pó troiano ou o filho de Tideu igual aos celestes com o auxílio de Palas? (14)

Na primeira estrofe, temos várias referências à épica. Vário, por exemplo, é um nome sempre associado a esse gênero. Se lembrarmos de uma passagem da Écloga IX (vv. 35-6), veremos que o nome de Vário aparece associado ao gênero épico:

nam neque adhuc Vario videor nec dicere Cinna 35 digna, sed argutos inter strepere anser olores.

["pois até aqui não pareço cantar coisas dignas de Vário

nem de Cina, mas gritar como pato entre cisnes melodiosos."]

Como explica João Pedro Mendes, Lúcio Vário Rufo é "amigo de Virgílio, poeta épico, reputado o maior especialista do gênero até o surgimento da Enéida. (...) Junto com Tuca, foi incumbido por Otaviano de publicar a Enéida após a morte do nosso poeta." (15) Conhecendo quem foi Vário, fica claro que esse representa o gênero épico.

Além disso, ao dizer que Vário estará Maeonii carminis alite (v. 2: "sob os auspícios do canto meônio"), o "eu" lírico faz outra 
HASEGAWA, Alexandre P. O Epodo X de Horácio e a recusa do gênero épico.

referência à épica, pois se diz que Homero, o eu(reth \j do gênero, nasceu na Meônia (Lídia). Esse poeta, portanto, é capaz de cantar os feitos da guerra (vv. 3-4), matéria própria desse gênero elevado.

Na segunda estrofe, temos claramente a recusa à épica e à tragédia juntamente, pois o "eu" lírico diz que não cantará nem a "grave cólera do filho de Peleu" (vv. 5-6) - mencionando a llíada , nem "as viagens por mar do dúbio Ulisses" (v. 7) - mencionando a Odisséia, outra modalidade épica, a do no/stoj- nem "a cruel casa de Pélope" - mencionando as tragédias, como a trilogia Orestéia, de Ésquilo, por exemplo, que conta parte da maldição lançada contra a casa de Pélope. Ou seja: há uma completa recusa dos gêneros elevados (grandia, v. 9) por quem pratica os humildes (tenues, v. 9), pois a Musa (v. 10) assim proibiu. Outro cantará dignamente (adequadamente) a matéria épica ("Marte", v. 13).

Com esses poemas líricos citados, queremos mostrar que Horácio recusa-se constantemente a praticar o gênero épico e associa-o sempre à viagem marítima. Ou seja: a recusa épica nos versos horacianos é uma recusa ao lançar-se ao mar, como fez o "fedorento Mévio" do Epodo X. Portanto, podemos dizer agora, com segurança, que a invectiva de Horácio é não só contra a poesia de má qualidade mas também contra o gênero épico praticado por aqueles que não têm ombros suficientes para suportar o peso da matéria do gênero elevado.

\section{Digressão:}

Antes de voltarmos ao Epodo $X$ de Horácio, queremos mostrar como a tópica da recusa épica sobreviveu em língua portuguesa e, curiosamente, em um poema épico, como Os Lusíadas, de Camões, pois até aqui vimos a recusa do gênero elevado em gêneros baixos, como o iambo e a lírica. Vejamos agora a recusa épica dentro da própria épica no famoso episódio do Velho do Restelo (Lus., IV, 102): 
$\bigcirc^{\prime}$ maldito o primeiro que no mundo

Nas ondas vela pôs em feco lenho!

Dino da eterna pena do profundo

Se he jufta lei que figo e tenho!

Nunca juizo algum alto e profundo

Nem cithara fonora ou vivo engenho

Te dê por iffo fama nem memoria,

Mas comtigo fe acabe o nome e gloria.

Porém, os nautas nestes versos estão fadados a uma viagem marítima bem sucedida, acometendo "o duvidoso mar num lenho leve", pois estamos no gênero épico, e não falta ao piloto desta navegação portuguesa a costumada virilidade e ombros capazes de suportar tão grande matéria. Aqui, diferentemente da "palidez lívida", da "lamúria não viril" e das "súplicas ao avesso Jove", do Epodo X, o(s) marinheiro(s), com "engenho e arte", não teme $(\mathrm{m})$ a "procellofa tempeftade,/ Nocturna fombra e fibilante vento (14)", e avança cada vez mais, plus ultra, com mais atrevimento $(1,27)$ :

Agora vêdes bem que cometendo

duvidofo mar num lenho leve

Por vias nunca ufadas, não temendo

De Africo e Noto a força, a mais fe atreve;

Que havendo tanto já que as partes vendo

Onde o dia he comprido e onde breve,

Inclinão feu propofito e perfia

A ver os berços onde nafce o dia.

\section{Propemtikoln às avessas:}

Além da leitura genérica que fizemos até aqui, queremos mostrar que o Epodo X é uma paródia de um propemtikoln ("discurso de boa viagem"), gênero muito praticado pelos poetas helenísticos. Enquanto a Ode I, 3 é um autêntico propemtiko\n 
HASEGAWA, Alexandre P. O Epodo X de Horácio e a recusa do gênero épico.

em que Horácio deseja uma boa viagem ao poeta Virgílio, que navegará no mar do gênero épico, o Epodo $X$ é o avesso disso, pois Horácio deseja uma péssima viagem ao poetastro Mévio, que desafia, sem condição de sucesso, o mar do gênero épico. Vejamos e analisemos brevemente a Ode I, 3:

Sic te diva potens Cypri,

sic fratres Helenae, lucida sidera,

ventorumque regat pater

obstrictis aliis praeter lapyga,

nauis, quae tibi creditum

debes Vergilium; finibus Atticis

reddas incolumem precor

et serves animae dimidium meae.

Illi robur et aes triplex

circa pectus erat, qui fragilem truci

commisit pelago ratem

primus, nec timuit praecipitem Africum

decertantem Aquilonibus

nec tristis Hyadas nec rabiem Noti,

quo non arbiter Hadriae

maior, tollere seu ponere volt freta.

Quem mortis timuit gradum

qui siccis oculis monstra natantia,

qui vidit mare turbidum et

infamis scopulos Acroceraunia?

Nequicquam deus abscidit

prudens oceano dissociabili

terras, si tamen impiae

non tangenda rates transiliunt uada. 
Audax omnia perpeti

gens humana ruit per vetitum nefas;

audax lapeti genus

ignem fraude mala gentibus intulit;

post ignem aetheria domo

subductum macies et noua febrium

terris incubuit cohors

semotique prius tarda necessitas

leti corripuit gradum.

Expertus vacuum Daedalus aera

pennis non homini datis;

perrupit Acheronta Herculeus labor.

Nil mortalibus ardui est;

caelum ipsum petimus stultitia neque

per nostrum patimur scelus

iracunda lovem ponere fulmina.

Assim a deusa poderosa de Chipre,

assim os irmãos de Helena, lúcidos astros,

e o pai dos ventos, tendo atado os

outros exceto o lápiga, te guiem, ó nau,

que me deves Vergílio confiado

a ti; que aos confins áticos, peço-te,

tu o devolvas incólume,

e preserves a metade da minha alma.

Tinha o roble e o bronze tríplice

ao redor do peito, o que primeiro lançou

o frágil remo ao feroz pélago,

nem temeu o precipitado Áfrico

que peleja com os Aquilōes, 
HASEGAWA, Alexandre P. O Epodo X de Horácio e a recusa do gênero épico.

nem as tristes Híades nem a raiva do Noto

- do que ele não há maior senhor do Adriático, quer queira alçar ou cessar as ondas.

Que marcha da morte temeu - que, com olhos secos, viu os monstros nadantes, - que viu o mar túrbido e os infames rochedos Acroceráunios?

Em vão um deus prudente separou as terras pelo incompatível oceano, se contudo os ímpios remos cruzam os mares que não se devem tocar.

Audaz em tudo ousar, a raça humana lançou-se ao vedado prodígio; A audaz descendência de Jápeto o fogo, com uma fraude perversa, às gentes trouxe; depois do fogo da mansão celeste roubado, a pobreza e uma nova tropa de febres caíram sobre as terras e a tardia necessidade da morte, antes remota, abreviou a sua aproximação.

Dédalo experimentou o espaço vazio, o ar, com as penas não dadas ao homem; um trabalho de Hércules venceu o Aqueronte.

Nada para os mortais há de árduo; o próprio céu acometemos por estultícia e nem sofremos por nosso crime que Jove lance iracundos raios.

Temos aqui, na Ode I, 3, a tópica da ousadia humana que desafia o que um deus prudente organizara. Do verso 21 ao 24 - 
Nequicquam deus abscidit/ prudens oceano dissociabili/ terras, si tamen impiae/ non tangenda rates transiliunt uada. ("Em vão um deus prudente/ separou as terras pelo incompatível/ oceano, se contudo os ímpios/ remos cruzam os mares que não se devem tocar.") -, o "eu" lírico deixa claro que não se deve tocar os mares; as naus, que assim fazem, são ímpias. $O$ poeta deve, no máximo, fazer uma viagem costeira, mas nunca navegar para o alto-mar. Podemos entender também que os mares intocáveis são os do gênero elevado.

Aquele que se lança à aventura épica, tendo "frágil remo", não teme os ventos, que produzem procelosas tempestades [vv. 10-16: qui fragilem truci/ commisit pelago ratem/ primus, nec timuit praecipitem Africum/ decertantem Aquilonibus/ nec tristis Hyadas nec rabiem Noti, / quo non arbiter Hadriae/ maior, tollere seu ponere volt freta. ("... o que primeiro lançou/ o frágil remo ao feroz pélago,/ nem temeu o precipitado Áfrico/ que peleja com os Aquilōes,/ nem as tristes Híades nem a raiva do Noto/ - do que ele não há maior senhor/ do Adriático, quer queira alçar ou cessar as ondas.")].

Há reminiscências desses últimos versos horacianos no trecho d'Os Lusíadas citado logo acima (I, 27, vv. 1-4: Agora vêdes bem que cometendo/ $O$ duvidofo mar num lenho leve/ Por vias nunca ufadas, não temendo/ De Africo e Noto a força, a mais fe atreve;). Destacamos as palavras que lembram os versos de Horácio: o "duvidofo mar" evoca o "feroz pélago"(vv. 10-11: ... truci/ ... pelago); "lenho leve", o "frágil remo" (vv. 10-11: ... fragilem .../ ... ratem), e a força dos dois ventos "Africo e Noto", "o precipitado Áfrico" (v. 12: ... praecipitem Africum) e "a raiva do Noto" (v. 14: ... rabiem Noti). Tal correspondência só reforça a leitura da viagem marítima como poesia épica.

Por ser tão perigosa essa viagem, o "eu" lírico pede proteção ao poeta Virgílio (vv. 1-4) e que a nau o devolva incólume (vv. 5-8). Porém, Mévio, figura do poetastro, no Epodo X, por tomar matéria acima de suas forças, é invectivado pelo "eu" iâmbico, que impreca aos ventos a destruição da nau (vv. 3-8) e deseja 
HASEGAWA, Alexandre P. O Epodo X de Horácio e a recusa do gênero épico.

depois que ele sirva de alimento aos mergulhões (vv. 21-22). Na Ode I, 3, portanto, temos o encômio de Virgílio, figura do bom poeta épico - e esse elogio torna-se ainda maior, pois há uma aversão a esse gênero -; no Epodo $X$, temos o vitupério contra Mévio, figura do mau poeta épico. Ou seja: de acordo com a divisão dos três gêneros de discurso (Ar. rhet., I, 3), temos os dois lados do epidíctico, o louvor e a censura, o nobre e o vil, Virgílio e Mévio, as Odes (virtudes) e os Epodos (os vícios).

Um ponto ainda da Ode I, 3 e do Epodo $X$ deixa claro que esses poemas devem ser lidos lado a lado: os ventos. Na Ode, o "eu" lírico pede que o pai dos ventos, Éolo, retenha todos, exceto - lápiga, vento do oeste e favorável para Virgílio ir da ltália a Grécia; no Epodo, o "eu" iâmbico conclama três ventos para destruírem a nau de Mévio: o Austro (v. 4), vento do sul; o Euro (v. 5), vento do leste, e o Aquilão (v. 7), vento do norte. Ou seja: dos quatro cantos do mundo, um vento, o do oeste, é bom, virtuoso e favorável à navegação; os outros três, do sul, leste e oeste são ruins, viciosos e desfavoráveis à navegação. Portanto, não é à toa que o Epodo $X$ é o avesso da Ode l, 3, um propemtikoln às avessas, como dissemos inicialmente.

A dimensão religiosa:

O Epodo $X$ de Horácio ainda pode ser considerado iambo em dimensão religiosa, a defixio, o encantamento, uma fórmula de caráter mágico contra alguém. Dó início [v. 1: "Solta, sob mau augúrio, parte a nau" (Mala soluta nauis exit alite)] ao fim do poema [vv. 23-24: "imolar-se-ão para as Tempestades/ uma cordeira e um bode lascivo." (libidinosus immolabitur caper/et agna Tempestatibus.)], percebemos a dimensão religiosa desses versos iâmbicos. É uma maldição mágica contra Mévio para que esse seja destruído.

Ubaldo Lugli (17) assim comenta o que eram as tabulae defixionis: "Instrumentos particulares da maldição 'mágica' grecoromana são as tabulae defixionis, cujo uso é atestado a partir do século $\mathrm{V}$ a. C. Trata-se de tabuinhas em geral de chumbo (associ- 
ado à morte por sua cor, frieza e peso, o plumbum é também o metal de Saturno, a stella nocens [= estrela aziaga]), sobre as quais vinham inscritas as fórmulas imprecatórias e que, depois de ser pregadas para dar à maldição um caráter de necessidade (a Anánke é representada com pregos e cunhas de bronze; Hor. Od. $1,17-9 ; 3,24,5-7)$, eram 'enviadas' às divindades infernais a que era consagrada a vítima, ao ser depostas em um sepulcro ou em lugar de caráter ctônico como poços e pântanos (La Penna, 1957). Às vezes as tabulae defixionis apresentam caráter erótico, objetivando a obter a sujeição física daquele por quem se tem desejo; na maior parte dos casos, porém, seu objetivo é ruína de um inimigo". (Negrito nosso)

Como é evidente no epodo, o "eu" iâmbico formula uma série de imprecações contra Mévio com o objetivo de vê-lo destruído, como se fosse uma tabula defixionis. O Epodo de Horácio, que é um encanto (18), é a própria fixação das imprecações, que dá à maldição o caráter de necessidade. Caso o encantamento seja realizado e o poetastro torne-se comida para os mergulhōes, o "eu" iâmbico promete imolar às Tempestades - elevadas à dignidade de divindades - uma cordeira e um bode lascivo.

Analisemos ainda por que o "eu" iâmbico promete uma cordeira e um bode. Esse é oferecido, porque assim como o bode é malcheiroso, assim Mévio, objeto da invectiva, é fedorento, pois o que se oferece para imolação sempre tem uma íntima relação com o que se pede. Como aqui se deseja a morte do "fedorento Mévio", imola-se um animal fétido (19). Com isso o "eu" iâmbico não só rebaixa o adversário ao ressaltar aspectos torpes mas também ao compará-lo com um animal, por assim dizer, 'vicioso'.

Além do mal cheiro, o bode é considerado, já pelos antigos, como um animal lascivo. Assim Sérvio (Comm. in Verg. Buc. III, 8), citando o Epodo X, comenta um passo das Bucólicas (III, 8): TRANSVERSA TVENTIBVS HIRCIS hircos, id est capros, libidinosa constat esse animalia: unde Horatius libidinosus immolabitur caper et agna Tempestatibus. [" 'COM OS BODES OBSERVANDO DE TRAVÉS' bodes, isto é capros, consta que são animais lascivos. Por isso 
HASEGAWA, Alexandre P. O Epodo X de Horácio e a recusa do gênero épico.

(escreveu) Horácio: 'imolar-se-ão para as Tempestades/ uma cordeira e um bode lascivo"."] O "eu" iâmbico, portanto, ressalta outro aspecto vicioso do animal para rebaixar ainda mais o seu oponente.

Não bastasse isso, o bode é considerado o de menor valor, o mais baixo, dentro do mundo bucólico, seja em Teócrito, seja em Virgílio. De acordo com Filárgiro (Expl. in Verg. Buc. Prooem.): Tria genera pastorum sunt, qui dignitatem in Bucolicis habent, quorum minimi caprarii, paulo honoratiores opiliones, honoratissimi bucolici. ["Três são os gêneros de pastores, que têm dignidade nas Bucólicas, dos quais os de cabras (ou bodes) são os menos dignos; um pouco mais dignos, os de ovelhas; os mais dignos (de todos), os de bois."]

Tal divisão, embora não sistemática e completa como a de Filárgiro, já aparece nos versos de Teócrito (Id. I, v. 86), quando Priapo rebaixa Dáfnis, dizendo que antes era chamado vaqueiro (elevado), mas agora mais parece um cabreiro (baixo):

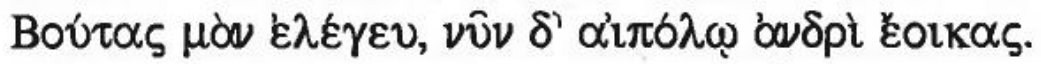
breiro."]

["Chamavam-te de vaqueiro, agora assemelhas-te a um ca-

Mévio, desejando ser elevado, poeticamente, ao cantar matéria épica, é rebaixado pelo "eu" iâmbico ao ser comparado com o bode, pois não é apto àquele gênero. $O$ poetastro, ao praticar - gênero épico, por não saber descriptas servare vices operumque colores (Hor., A. P., v. 86: "observar as funções descritas e as características dos gêneros"), cai no vicioso, assemelhando-se ao bode, que é, por assim dizer, 'vicioso'.

A cordeira, porém, aparece ao lado desse animal para tornar o oferecimento aceitável, para mostrar a justiça do pedido. Oferece-se algo bom - e não só o vicioso - para que a imprecação se realize (20). 
Do crescimento da raiva:

Quanto à disposição do poema, podemos dizer que a raiva aumenta à medida que surgem novos versos. No início (vv. 1-2), o "eu" iâmbico rebaixa o adversário ressaltando um aspecto vicioso - o fedor - e deseja uma má viagem para Mévio. Em seguida (vv. 3-14), a raiva aumenta, pois se deseja que os ventos destruam a nau, tornando o mar agitadíssimo, e que à noite não surja nenhum astro e o céu permaneça inteiramente negro. Antes do desfecho (vv. 15-20), ressalta novamente a destruição da nau e focaliza o medo de Mévio, rebaixando de novo o oponente, mas agora ao mostrar a não virilidade dele e a perda do controle da embarcação. Por fim (vv. 21-24), não contente com a destruição da nau, quer, com uma raiva ainda maior, a destruição total de Mévio: que ele morra e se torne comida de aves.

Esse crescimento da raiva, que aparece em mais de um Epodo de Horácio, é característica genérica, e, segundo Hefestiāo, tem

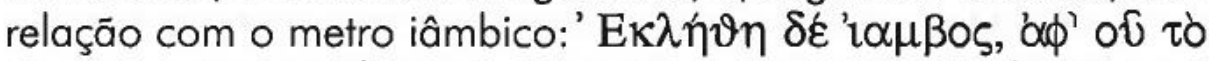

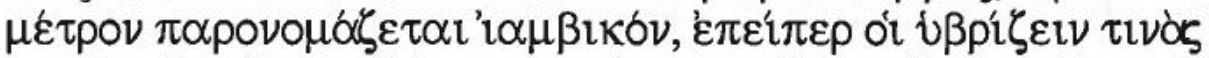

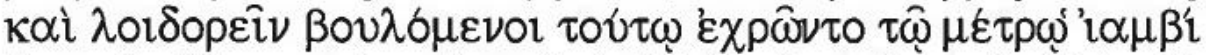

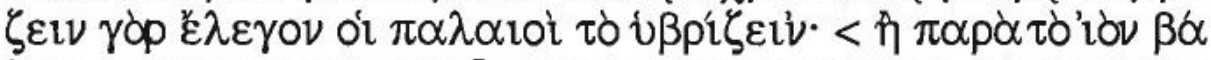

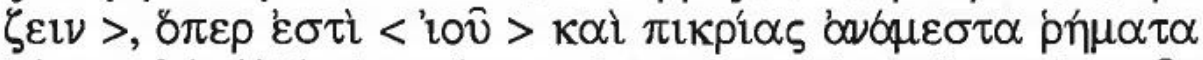

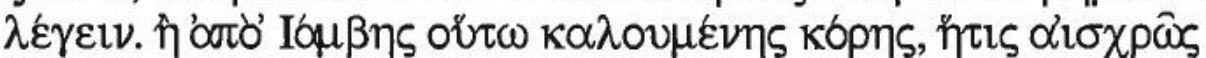

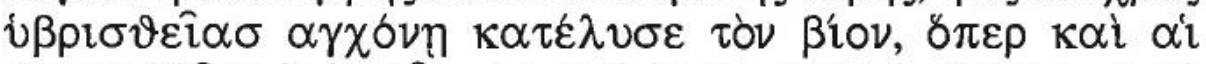

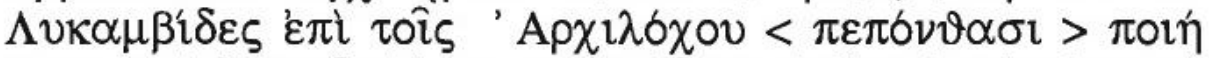

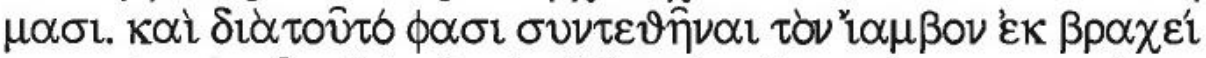

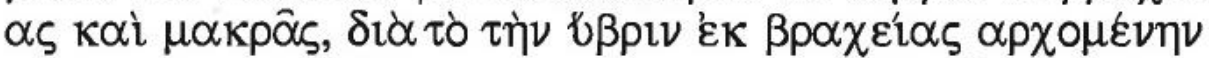

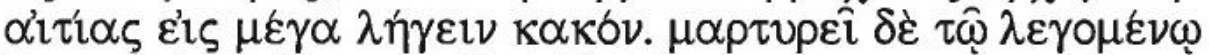

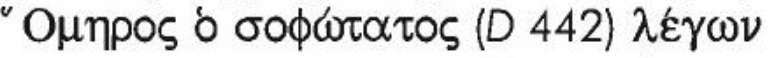

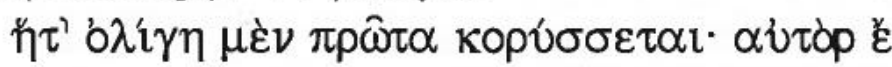

$\pi \varepsilon \imath \tau \alpha$

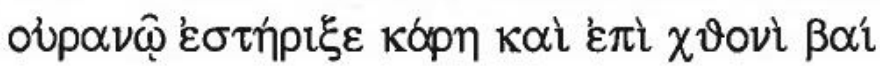

vel. (21) 
HASEGAWA, Alexandre P. O Epodo X de Horácio e a recusa do gênero épico.

["(O pé) É chamado iambo, a partir do que o metro recebe a designação 'iâmbico', porque os que desejavam maltratar e insultar pessoas utilizavam este metro (pois os antigos $\mathrm{u}(\mathrm{bri} / \mathrm{zein}$ diziam i)ambi/zein); ou por causa de tol i)oln ba/zein, 'proferir algo venenoso', isto é, falar palavras plenas de veneno e cólera; ou por causa de lambe, garota que tinha esse nome e que, insultada torpemente, deu cabo da vida por enforcamento, como também as filhas de Licambes, em vista dos poemas de Arquíloco cheios de ódio. Por isso diz-se também que o iambo é composto de uma (sílaba) breve e uma longa, pois a híbris, começando numa acusação pequena, termina num grande mal. Testemunha- Homero, o mais sábio, quando diz: (a Discórdia de furores sem medida, irmã companheira de Ares, matador de homens) que, se veste pequena de início, e logo depois com o rosto fere o céu, enquanto caminha sobre a terra. (22)"]

Casamento perfeito entre metro e matéria neste Epodo, que é modelo do gênero iâmbico, ao invectivar o poetastro Mévio. Aqui Horácio mostra "os iambos Pários/ ao Lácio, seguindo o ritmo e o ânimo/ de Arquíloco, não a matéria e as palavras que atacam Licambes." (Epist., 1, 19, vv. 23-25: ... Parios ego primus iambos/ ostendi Latio, numeros animosque secutus/Archilochi, non res et agentia verba Lycamben.)

\section{NOTAS}

1. 36,40 e 54 , por exemplo.

2. Diomedes, Artis Grammaticae Libri III, P. 485, $11-17$ (Keil).

3. Trad.: João Angelo Oliva Neto.

4. F. Villeneuve, "Analyse métrique des Odes" In Horace. Odes et épodes. Paris: "Les Belles Lettres", 1927, p. LXXXII: "Dans le sénaire le tribaque peut remplacer l'ïambe surtout au $2^{\circ}$ pied; le spondée se rencontre souvent aux pieds impairs, le dactyle paraît aux pieds 1 et 3 , l'anapeste, aux pieds 1 et 5 . Dans le quaternaire, le spondée est très fréquent au $3^{e}$ pied, frequent aut $j^{\text {er }}$ 
où l'on trouve aussi, par exception, le dactyle. Le tribaque se recontre une fois, au $2^{e}$ pied."

5. Essas duas primeiras substituiçōes podem ser verificadas no sétimo verso.

6. Temos um anapesto no verso 19 , mas no segundo pé.

7. O segundo verso exemplifica isso.

8. Diz o prórpio Horácio (A. P., v. 357): sic mihi, qui multum cessat, fit Choerilus ille, ["assim, para mim, quem muito falha, torna-se aquele famoso Quérilo,"]. Esse foi um poeta, que, segundo a lenda, era protegido de Alexandre, que The prometeu pagar uma moeda de ouro por cada bom verso, mas, por cada mau verso, dar-lhe-ia uma chicotada. Dizem que morreu de tanto apanhar. Horácio cita-o, em oposiçāo a Homero, como símbolo do mau poeta. Ver também Hor., Epist., II, 1, vv. 233-234.

9. "Da Parca foi preado: foi apanhado pela morte"

10. "Favorável: é que, apesar de ter atirado as naves de Ajax contra as rochas de Giras, Netuno (Posêidon) impediu que ele morresse sob a ira de Atena, nesse momento. E teria continuado vivo, se não proferisse uma impiedade."

11. Homero. Odisséia. Tradução de Manuel Odorico Mendes e edição de Antonio Medina Rodrigues. Sáo Paulo: Edusp, 1996, p.114

12.) "Vós, que escreveis, tomai a matéria adequada às vossas forças e meditai por longo tempo o que vossos ombros recusam, o que conseguem suportar."

13. Trad.: Ariovaldo Augusto Peterlini.

14. Trad.: Dante Tringali.

15. J. P. Mendes. Construçâo e arte das Bucólicas de Virgílio. Porto: Almedina, 1997, p.304, nota 20.

16. Lus., IV, vv. 1-2.

17. Ubaldo Lugli. La magia a Roma. Genova: ECIG, 1989, p. 97. Trad.: João Angelo Oliva Neto.

18. Para o sentido da palavra epodo ( $\dot{\varepsilon} \pi \omega \delta \phi \lambda)$ como encantamento, um canto contra alguém, temos o testemunho de Platão, Leis, 909b: [...]

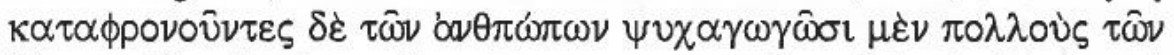

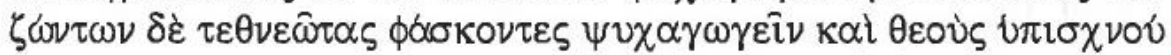

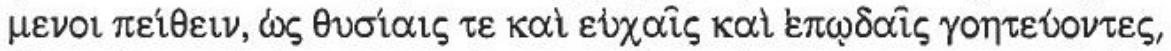
("[aqueles que] desprezam os homens afirmando poder evocar os espíritos de muitos entre os vivos e os espíritos dos mortos, prometendo persuadir os deuses, enfeitiçando-os com sacrifícios, preces e encantamentos,"). Trad.: João Angelo Oliva Neto. 
HASEGAWA, Alexandre P. O Epodo X de Horácio e a recusa do gênero épico.

19. Embora seja uma etimologia falsa, Varrāo, em De L. L., I, 4, 19, explica que os sabinos diziam fircus em vez de hircus, por ser um animal fétido. $O$ mal cheiro, porém, apesar da etimologia, não é falso.

20. Agradecemos e acolhemos aqui a sugestão do profo João Angelo Oliva Neto.

21. Comentários em Hefestião, Escólios B (Consbruch, Hephaestionis Enchiridion Stutgardiae: Teubner, 1971, p. 281).

22. Trad. João Angelo Oliva Neto.

\section{BIBLIOGRAFIA}

ARISTÓTELES. Retórica. Lisboa: Imprensa Nacional-Casa da Moeda, 1998.

CAMÕES, L. Os Lusíadas - comentados por Augusto Epiphanio da Silva Dias. Porto: Magalhães \& Moniz, 1910.

FILARGÍRIO, J. Iunii Philargyrii grammatici explanatio in Bucolica Vergili, vol. III. Thilo, G. et Hagen, H. Leipzig, Teubner, 1887 (Reimpressão: New York, Georg Olms Verlag, 1986).

HOMERO. Odisséia. Tradução de Manuel Odorico Mendes e edição de Antonio Medina Rodrigues. São Paulo: Edusp, 1996.

HORACE. Epistles Book II and Epistle to the Pisones ('Ars Poetica'). Edited by Niall Rudd. Cambridge: Cambridge U. P.1999. . Odes et épodes. Texte établi et traduit par F. Villeneuve. Paris: “Les Belles Lettres", 1927. . Oeuvres d'Horace. Texte publié d'après les travaux les plus recents par A. Waltz. Paris: Garnier Frère, [s.d.]. LUGLI, Ubaldo. La magia a Roma. Genova: ECIG, 1989. OLIVIER, Frank. Les épodes d'Horace. Paris: Payot \& Cie., 1917. Poesia lírica Latina. Organização Maria da Gloria Novak e Maria Luiza Neri. São Paulo: Martins Fontes, 1992.

QUINTILIAN. The institutio oratoria v.I-IV. Butler, H.E. The Loeb Classical Library. Harvard: University Press, 1979. 
SÉRVIO. Seruii Grammatici qui feruntur in Vergilii carmina commentarii vol. III, Thilo, G. et Hagen, H. Leipzig, Teubner, 1887 (Reimpressão: New York, Georg Olms Verlag, 1986).

TEOCRITO. Idilli e epigrammi. Milano: BUR Classici greci e latini, 2001.

TRINGALI, Dante. A Arte Poética de Horácio. São Paulo: Musa, 1994 . Horácio poeta da festa: navegar não é preciso. São Paulo: Musa, 1995.

VIRGIL. Eclogues. Edited by Robert Coleman. Cambridge: Cambridge U. P. 1998.

WEST, Martin. Studies in Greek elegy and iambus. Berlin/ New York: Walter de Gruyter, 1974. 